\title{
KEPUASAN PELANGGAN TERHADAP PELAYANAN JASA PENGUJIAN DI INSTANSI $X$
}

\author{
Jimmy Abdel Kadar ${ }^{1, \Xi)}$, Asep Rahmat Hidayat ${ }^{2)}$ \\ Lembaga Ilmu Pengetahuan Indonesia \\ Email : ${ }^{1}$ jimmy.ak3@gmail.com
}

\begin{abstract}
Agency X has implemented ISO 9001 with periodic evaluation. The research objective was to determine the quality of testing services. Measurement data for 2015, 2016, and 2017. The methodology used is quantitative descriptive narrative, data collection by a survey, observation, and interviews. Based on internal calculations of agency X, Permenpan number 14 of 2017, and 5 servqual dimensions. Results calculation of customer satisfaction in 2015, 2016, and 2017 have achieved the quality target. Customer dissatisfaction gap by $25 \%$ annually, one of the reasons is the duration of testing time that exceeds the provisions, due to additional requests from customers.
\end{abstract}

Keywords: Customer satisfaction, service, servqual

\begin{abstract}
ABSTRAK
Instansi X telah menerapkan ISO 9001 dengan evaluasi rutinitas manajemen. Tujuan penelitian untuk mengetahui kualitas jasa pengujian. Data pengukuran yang diizinkan, tahun 2015, 2016 dan 2017. Metodologi yang digunakan adalah kuantitatif deskriptif naratif, pengambilan data dengan survei, observasi dan wawancara. Berbasis perhitungan internal instansi X, Permenpan nomor 14 tahun 2017 dan 5 dimensi servqual. Hasil perhitungan kepuasan pelanggan di instansi X pada tahun 2015, 2016 dan 2017 telah mencapai target sasaran mutu. Gap ketidakpuasan pelanggan sebesar 25\% tiap tahunnya, salah satunya adalah durasi waktu pengujian yang melebihi ketentuan, karena adanya permintaan tambahan dari pelanggan.
\end{abstract}

Kata kunci: Kepuasan pelanggan, layanan jasa, servqual.

\section{PENDAHULUAN}

Kualitas layanan yang baik dan memadai dari suatu penyelenggara layanan akan memberikan suatu ketertarikan dari pengguna layanan/konsumen, untuk membuat ikatan terhadap penyelenggara layanan tersebut. Ikatan ini dalam jangka panjang memungkinkan penyelenggara layanan untuk memahami dengan seksama harapan pelanggan/konsumen serta kebutuhan mereka.

Keluhan pelanggan merupakan hal lazim terjadi, dan keluhan ini perlu penangan yang cermat, karena pelanggan merupakan bagian dari proses layanan jasa pengujian. Penangan keluhan pelanggan dapat dilakukan terstruktur atau pun dapat dilakukan dengan cara membuat aturan sendiri dan disahkan oleh manajemen. Salah satu bentuk penanganan keluhan pelanggan yaitu dengan melakukan pengukuran sebagai bagian dari umpan balik.

Instansi $\mathrm{X}$ memberikan layanan jasa pengujian dan telah menerapkan ISO 9001[1]. proses layanan pengujian ini tidak terlepas dari pengukuran sebagai umpan balik bagi manajemen. Umpan balik merupakan hal yang lumrah bagi setiap organisasi yang melakukan layanan jasa, dengan tujuan untuk mengetahui kepuasan pengguna layanan. Aspek yang menjadi variabel pertanyaan meliputi keseluruhan proses dari hulu ke hilir, dan responden merupakan pelanggan layanan jasa pengujian.

Menpan RB mengeluarkan cara dalam pengukuran kepuasan pelanggan dan tertuang dalam Permenpan RB nomor 14 tahun 2017 tentang pedoman penyusunan survei kepuasan masyarakat unit penyelenggara pelayanan publik[2]. 
Pengukuran dengan metode lainnya dengan menggunakan servqual. Menurut Parasuraman [3][4][5], ada 5 dimensi servqual yang sering digunakan yaitu; RATER (Reability, Assurance, Tangibles, Empathy, Responsiveness). Pengukuran dengan metode ini dapat mengidentifikasi kekuatan dan kelebihan pada layanan jasa, dan dapat mengetahui kesenjangan atau gap antara persepsi dan harapan pelanggan.

Pengukuran ini bertujuan untuk mengetahui persepsi dan harapan pelanggan dan evaluasi bagi pengelola layanan jasa. Masalah yang muncul terdapat kesenjangan responden yang kurang puas dengan rata-rata 25\% tiap tahunnya.

\section{METODE PENELITIAN}

Menggunakan metodologi kuantitatif deskriptif naratif dan secara umum melaksanakan penelitian dengan pengumpulan data dengan cara survei, observasi, dan wawancara. Data pelaksanaan merupakan deret waktu (time series) antara tahun 2015, 2016 dan 2017 (diizinkan). Jumlah pelanggan layanan jasa pengujian relatif fluktuatif antara 15 hingga 20 pelanggan per tahun.

\section{Responden}

Responden pertama merupakan masyarakat industri sebagai pengguna jasa pengujian. Teknik pengambilan sampel menggunakan non probability sampling, dan sampling jenuh merupakan cara yang digunakan karena jumlah responden tersebut sedikit dan kurang dari 30 orang tiap tahunnya [6][7]. Dengan demikian semua responden menjadi populasi yang akan diukur.

Responden kedua merupakan pakar/ahli dalam mengklasifikasikan kategori ketentuan layanan yang telah disusun oleh pengelola layanan. Pakar/ahli merupakan pejabat pengelola dan manajer mutu yang berwenang dan akademisi yang berbasis pada layanan masyarakat. Hasil dari rensponden kedua digunakan sebagai penghubung hasil dari kuisioner dengan servqual dengan 5 dimensi [8].

\section{Wawancara}

Wawancara sebagai verifikasi data yang telah dibuat dan untuk menjawab gap yang ada. Respondennya merupakan pelanggan layanan jasa, manajer mutu, dan penanggung jawab operasional instansi $\mathrm{X}$.

\section{Analisis data}

Kepuasan pelanggan ditinjau dari mutu instansi $\mathrm{X}$ yang telah menerapkan ISO 9001 dengan ketentuan target sasaran mutu untuk kepuasan pelanggan adalah lebih dari sama dengan 80. Permenpan nomor 14 tahun 2017 tentang Indeks kepuasan masyarakat (IKM) juga digunakan sebagai acuan dalam menetapkan "mutu pelayanan" dan "kinerja unit pelayanan" [9], dan servqual dengan 5 dimensi RATER.

\section{HASIL DAN PEMBAHASAN}

\section{Hasil}

Berdasarkan Pedoman Mutu ISO 9001 pada instansi $\mathrm{X}$ yang mengharuskan kegiatan layanan jasa terukur, maka diperlukan instrumen yang dapat memenuhi pengukuran yang diperkukan. Pada pedoman Mutu tersebut, target sasaran mutu kepuasan pelanggan adalah 80, dengan pemahaman jika nilai hasil perhitungan bernilai lebih dari sama dengan 80, maka kepuasan pelanggan pada Instansi $\mathrm{X}$ telah tercapai, dan sebaliknya.

Pembuatan instrumen yang berupa kuisioner telah melalui uji validitas dan uji reliabilitas. Uji validasi yang dilakukan dengan melihat konstruksi pertanyaan pada kuisioner sejalan dengan kondisi yang diukur. 
Tabel. 1 Hasil rata-rata kepuasan pelanggan pengujian tahun 2015, 2016 dan 2017

\begin{tabular}{|c|c|c|c|}
\hline \multirow{2}{*}{ Responden } & \multicolumn{3}{|c|}{ Tahun } \\
\cline { 2 - 4 } & $\mathbf{2 0 1 5}$ & $\mathbf{2 0 1 6}$ & $\mathbf{2 0 1 7}$ \\
\hline $\mathbf{0 1}$ & 92.3 & 83.5 & 97.2 \\
\hline $\mathbf{0 2}$ & 85.0 & 71.5 & 85.0 \\
\hline $\mathbf{0 3}$ & 81.0 & 98.5 & 74.0 \\
\hline $\mathbf{0 4}$ & 78.9 & 79.4 & 83.5 \\
\hline $\mathbf{0 5}$ & 75.7 & 92.50 & 77.0 \\
\hline $\mathbf{0 6}$ & 80.5 & 88.3 & 99.0 \\
\hline $\mathbf{0 7}$ & 65.1 & 82.5 & 82.5 \\
\hline $\mathbf{0 8}$ & 85.0 & 78.0 & 70.0 \\
\hline $\mathbf{0 9}$ & 90.0 & 81.5 & 92.0 \\
\hline $\mathbf{1 0}$ & 88.0 & 98.0 & 93.4 \\
\hline $\mathbf{1 1}$ & 87.0 & 71.0 & 100.0 \\
\hline $\mathbf{1 2}$ & 82.3 & 87.5 & 80.0 \\
\hline $\mathbf{1 3}$ & 78.3 & 85.7 & 92.5 \\
\hline $\mathbf{1 4}$ & 95.5 & 98.0 & 72.0 \\
\hline $\mathbf{1 5}$ & 80.5 & 99.6 & 96.5 \\
\hline $\mathbf{1 6}$ & & 96.5 & 78.0 \\
\hline $\mathbf{1 7}$ & & 98.0 & 93.0 \\
\hline $\mathbf{1 8}$ & & 77.0 & 80.0 \\
\hline $\mathbf{1 9}$ & & 100.0 & \\
\hline $\mathbf{2 0}$ & & 81.5 & \\
\hline Rata-rata & 83.0 & 87.4 & 85.2 \\
\hline
\end{tabular}

sumber : hasil data olahan 2015, 2016, 2017 (primer)

Uji reliabilitas dilakukan dengan melihat kecenderungan pemahaman responden pada pertanyaan. Uji coba dilakukan auditor internal dan auditor external. Pada pelaksanaan pengukuran responden merupakan pengguna jasa penggujian instansi X. Hasil kuisioner dilakukan validasi tahap akhir untuk mengetahui hasil kuisoner tidak boleh kosong.

Dari tabel 1 dapat dilihat bahwa hasil rata-rata kuisioner kepuasan pelanggan pengujian tahun 2015 adalah 83, 2016 adalah 87,4 dan 2017 adalah 85,2.

\section{Pedoman Mutu ISO 9001}

Berpegangan pada Pedoman Mutu instansi X yang mengacu pada ISO 9001, maka nilai hasil perhitungan dari tahun 2015, 2016 dan 2017, secara langsung telah memenuhi target sasaran mutu, dengan demikian capaian sasaran mutu instansi $\mathrm{X}$ telah terpenuhi.

\section{Permenpan Nomor 14 Tahun 2017}

Tabel 1, hasil perhitungan dari tahun 2015, 2016 dan 2017 jika dipandang dari Permenpan nomor 14 tahun 2017 sebagai referensi dan rujukan pada Indeks Kepuasan Masyarakat (IKM), maka sasaran mutu tersebut telah memenuhi kriteria, karena nilai pada tahun 2015, 2016 dan 2017 berada diantara nilai interval konversi yaitu pada interval 76,61 - 88,30, dan “mutu pelayanan nilai B" dengan keterangan "kinerja unit pelayanan adalah Baik”.

\section{Service Quality (Parasuraman, Reability, Assurance, Tangibles, Empathy, Responsiveness)}

Melihat kedalaman kepuasan pelanggan, dapat menggunakan teori servqual. Diperlukan penyelarasan kuisioner yang ada kedalam servqual. Secara umum terdapat 5 dimensi yaitu reliability, assurance, tangibles, emphaty, dan responsivenes. Pelaksanaan penyelarasan diperlukan untuk menggolongkan pertanyaan kuisioner yang sudah ada kedalam 5 (lima) dimensi servqual. Pelaksanaan penggolongan ini dengan membuat kuisioner, dan respondennya melibatkan para ahli dari akademisi dan pengelola pelaksanaan jasa pengujian.

Penggolongan ini diperlukan untuk memetakan pertanyaan sesuai denan kategori servqual. Kuisioner tahap ini telah dilakukan validitas dan reliabilitas dengan cara menyebarkan angket untuk kalangan industri dan pengelola pengujian, sebagai pendahuluan untuk dikoreksi baik dari sisi bahasa, konten dan pendalaman konten. Pemetaan pertanyaan pada kuisioner kepuasan pelanggan instansi X berupa; Reability (keandalan), yaitu kemampuan untuk memberikan pelayanan yang telah dijanjikan secara handal dan akurat. Kuisioner tergabung dalam dimensi ini adalah pertanyaan Kecepatan Waktu 
Pengujian dan Ketepatan Waktu Penyerahan Hasil Uji; Assurance (jaminan), yaitu meliputi pengetahuan dan kesopanan karyawan dalam melayani pelanggan, serta kemampuan menjaga kepercayaan pelanggan. Kuisoiner yang tergabung dalam dimensi ini adalah Manfaat Hasil Pengujian; Tangibles (bukti fisik), yaitu meliputi penampilan fasilitas fisik, peralatan, tenaga kerja, dan alat komunikasi. Kuisoiner yang tergabung dalam dimensi ini adalah Kenyamanan Lingkungan/Ruangan, Biaya Pengujian, dan Sistematika Penyajian Laporan; Empathy (empati), yaitu kepedulian dan perhatian individual yang disediakan oleh perusahaan kepada pelanggan. Kuisoiner yang tergabung dalam dimensi ini adalah Keramahan Petugas dan Kesiagaan Petugas; dan Responsiveness (daya tanggap), yaitu kemampuan untuk membantu pelanggan dan menyediakan layanan dengan segera. Kuisoiner yang tergabung dalam dimensi ini adalah Kejelasan Informasi Pengujian dan Kemudahan Memperoleh Informasi. Pada tabel 2, semua dimensi dari tahun 2015, 2016 dan 2017 bernilai diatas 80, dengan demikian bahwa dengan menggunakan pendekatan servqual telah memenuhi target sasaran mutu.

Tabel 2. Perhitungan berdasarkan metode servqual tahun 2015, 2016 dan 2017

\begin{tabular}{lccc}
\hline \multirow{2}{*}{\multicolumn{1}{c}{ Dimensi }} & \multicolumn{3}{c}{ Tahun } \\
\cline { 2 - 4 } Reability & $\mathbf{2 0 1 5}$ & $\mathbf{2 0 1 6}$ & $\mathbf{2 0 1 7}$ \\
Assurance & 80,0 & 85,3 & 84,2 \\
Tangibles & 86,7 & 89,8 & 88,4 \\
Empathy & 83,1 & 86,1 & 85,3 \\
Responsiveness & 83,3 & 89,4 & 86,4 \\
sumber : hasil data & olahan & 2015,3 & 86,6 \\
(primer)
\end{tabular}

\section{Pembahasan}

Pengukuran kepuasan pelanggan dengan metode kuisioner ISO 9001, pedekatan dengan Permenpan nomor 14 tahun 2017 dan pendekatan dengan servqual, menghasilkan nilai diatas angka 80 dengan pemahaman bahwa telah mencapai target sasaran mutu instansi X. Pembahasan dengan servqual lebih mendalam dalam menganalisis dan menjelaskan dengan instrumen tambahan. Sehingga dapat memberikan informasi lebih pada manajemen pengelola layanan jasa.

\section{Kesenjangan Harapan dan Kinerja}

Pada tabel 1 dengan memperhatikan nilai setiap responden. Secara keseluruhan terdapat kesenjangan berkisar 25\% setiap tahunnya, dari jumlah responden.

Dilakukan wawancara pada manajer mutu dan penanggung jawab operasional untuk merespon kesenjangan berkisar $25 \%$ untuk setiap tahun yang menjadi data penelitian.

Menurut Parasuraman, Zeithaml dan Berry [10][11], layanan yang dirasakan kurang puas oleh pelanggan dapat dijelaskan pada gap yang berpengaruh:

1. Gap persepsi manajemen - harapan pelanggan. Berdasarkan klausul 9 pada panduan mutu ISO 9001:2015 pada instansi $\mathrm{X}$, harus menganalisa harapan dan kebutuhan pelanggan, untuk solusi masalah tersebut manajemen instansi $\mathrm{X}$ mengundang semua stakeholder yang berkepentingan dengan layanan jasa pengujian, untuk sosialisasi migrasi dari Sistem Manajemen Mutu (SMM) lama ke SMM yang baru, dan juga sekaligus hak dan kewajiban dari pelanggan. Persepsi dari gap ini juga digali dari pelanggan yang menyatakan bahwa adanya kekeliruan pemahaman setelah sosialisasi migrasi ke ISO 9001:2015. Kekeliruan yang terjadi adalah adanya pemahaman bahwa instansi $\mathrm{X}$ dapat melakukan semua layanan jasa pengujian yang ada di industri, walau pada saat sosialisasi telah dinyatakan kemampuan Instansi $\mathrm{X}$ dalam menguji. Sisi lain gap yang sering bermasalah pada pelanggan adalah tanggal selesainya pengujian. Perbedaan pemahaman ini yang sering terjadi sehingga dilakukan diskusi ulang agar masalah dapat terpecahkan. 
2. Gap persepsi manajemen - standar pelayanan, gap spesifikasi kualitas jasa penyampaian pelayanan. Kesenjangan pada gap ini berpotensi positif, karena luaran hasil uji berupa sertifikat dan laporan hasil uji melebihi dari harapan. Pelanggan diberikan laporan yang detail dari produk yang dihasilkan dan tidak ada pada layanan jasa pengujian lainnya.

3. Gap standar pelayanan - layanan pengiriman, kesenjangan penyampaian pelayanan. Pada gap ini terjadi karena kesenjangan informasi kepada pelanggan terkait jadwal yang berubah sewaktu-waktu, kurangnya petugas dilapangan. Saat ini banyak pekerjaan di instansi X dikerjakan oleh peneliti, sehingga potensi terjadinya keterlambatan karena interupsi dari atasan terkait penelitian dan pekerjaan lainnya memungkinkan terjadi.

4. Gap layanan pengiriman - persepsi pelanggan. Gap penyampaian komunikasi layanan pemasaran, dengan kata lain terdapat kesenjangan komunikasi dengan eksternal. Pada gap ini mempunyai pemahaman yang positif, karena pelanggan diberikan kesempatan untuk diskusi teknis terkait produk yang akan diuji, layanan pengiriman (negara tujuan produk akan dipasarkan). Pelanggan akan diberikan jalan keluar terkait kesulitan pengujian untuk produk karena harus mengikuti standar pada negara tujuan. Pada tahap ini pelanggan diberikan kemudahan.

5. Gap persepsi pelanggan - ekspektasi pelanggan. Gap ini berpotensi terjadi pada penentuan jadwal pengujian, pemahaman dari pelanggan akan selesai sesuai dengan kebutuhan dan hasil diskusi diawal. Kendala waktu yang tertera dijadwal selalu menjadi perhatian pelanggan.

Sisi lainnya dari wawancara yaitu penjelasan terkait biaya yang relatif tinggi. Menurut penjelasan manajer mutu, biaya pengujian sudah tertera dalam PNBP dari pemerintah sehingga instansi
$\mathrm{X}$ tidak punya kewenangan untuk mengubah harga sesuai penawaran langsung dari pelanggan. Jika ada keluhan terkait tarif akan tetap dicatat sebagai bahan masukan untuk disampaikan pada periode berikutnya sesuai perkembangan perubahan PNBP yang diminta oleh Pemerintah.

Gardu listrik yang menjadi infrastruktur vital mengalami gangguan (force major) sehingga layanan jasa pengujian pada tahun 2016, terhambat untuk beberapa waktu. Kondisi ini sudah diinformasikan pada pelanggan. Pada gap yang ke 4 permintaan akan penambahan petugas uji sudah dilakukan hingga tahun 2019, sangat terbatas dan belum memadai, sehingga keterlambatan penyelesaian pengujian beberapa kali terjadi. Keterlambatan dan progres pengujian tetap diinformasikan pada pelanggan.

Data perhitungan kepuasan pelanggan dan IKM dilakukan secara periodik sebagai bahan evaluasi. Manajemen instansi $\mathrm{X}$ dapat mengambil manfaat yang lebih dari sekedar data yang telah direkap. Manfaat lainnya yaitu dapat diketahui kelemahan dan kekurangan dari masing-masing unsur dalam penyelenggaraan pelayanan untuk masyarakat. Hasil evaluasi yang telah disahkan dan diperbaiki akan menjadi laporan kinerja pengelola layanan jasa pengujian. Laporan tersebut menjadi informasi dan data untuk penetapan kebijakan yang diperlukan; sebagai bagian dari Indeks kepuasan masyarakat instasi pusat terhadap pelaksanaan pelayanan publik; dapat memacu persaingan yang sehat terhadap penyelenggaraan pelayanan di lingkungan pemerintahan.

Menurut manajer mutu pengelola pengujian, pelanggan mengakui bahwa laporan hasil pengujian yang dilakukan oleh instansi X cukup memuaskan. Karena dalam laporan tersebut lebih mendalam dan memuat informasi yang diperlukan dalam pengujian ulang atau pengujian pembuktian dan dapat 
dilakukan oleh instansi lainnya sebagai pembanding. Tidak terjadi gap pada penyampaian pelayanan yang signifikan, dapat dilihat dari kuisioner sehingga tidak berpengaruh terhadap mutu layanan.

Pegawai laboratorium yang menjadi pelaku pengujian, fokusnya terbagi dengan penelitian yang sedang berlangsung. Maka pada saat diskusi teknis sering ditekankan oleh pengelola layanan tentang kondisi yang ada. Durasi pengujian sering terkendala, antara pengujian dan penelitian, dan sudah diinformasikan pada pelanggan pengujian.

\section{KESIMPULAN DAN SARAN}

\section{Kesimpulan}

Pengungukuran kepuasan pelanggan menggunakan instrumen ISO 9001:2015, pengukuran IKM dengan Permenpan nomor 14 tahun 2017 dan menggunakan metode servqual dengan data tahun 2015, 2016, dan 2017 pada instansi X, telah memenuhi target sasaran mutu kepuasan pelanggan jasa pengujian, karena nilai sasaran mutu telah lebih dari sama dengan 80. Nilai IKM pada tahun-tahun ini dengan mutu pelayanan " $B$ " dan Kinerja unit "Pelayanan Baik”.

Instrumen yang digunakan dalam pengukuran ini saling bertautan dan melengkapi dari ISO 9001, Permenpan nomor 14 tahun 2017, dan metode servqual.

Kesenjangan yang terjadi atau ketidakpuasan pelanggan berkisar 25\% dalam kurun waktu penelitian dapat dianalisis dengan metode servqual, dengan gap dan pengembangan parameter yang diperlukan, pada penelitian ini menjelaskan 5 gap. Gap tersebut menjelaskan kelemahan dari layanan jasa. Seperti perbedaan persepsi pelanggan pada panduan mutu sehingga harapan pada saat pengujian belum terpenuhi; durasi pengujian yang diluar ketentuan dan sudah diinformasikan pada pelanggan. Pengaruh gap ini membuat penilaian dari pelanggan jadi berkurang. Hasil penelitian ini secara langsung atau tidak langsung menjadi salah satu masukan dan bahan evaluasi bagi manajemen pengelola layanan jasa pengujian instansi $\mathrm{X}$.

\section{Saran}

Menggunakan permenpan nomor 14 tahun 2017 dan metode servqual dengan pengembangan parameter yang lebih detail, untuk penelitian berikutnya.

\section{Ucapan Terima kasih}

Penulis berterima kasih pada kepala Satker P2SMTP yang telah menjadi P2TP, Ibu Ika Fitriana Hapsari yang mengarahkan terbentuknya data pelanggan, dan pak Ade Khaerudin Taufiq selaku wakil manajemen mutu atas bantuan dan wawancaranya.

\section{DAFTAR PUSTAKA}

[1] International Standard Organization, "ISO 9001 Quality management systems-Requirements,” Int. Stand., 2008.

[2] Menpan RB, "Peraturan Menteri Pendayagunaan Aparatur Negara Dan Reformasi Birokrasi Republik Indonesia Nomor 14 Tahun 2017 Tentang Pedoman Penyusunan Survei Kepuasan Masyarakat Unit Penyelenggara Pelayanan Publik," Pedoman Penyusunan Survei Kepuasan Masy. Unit Penyelenggara Pelayanan Publik, 2017.

[3] A. Parasuraman, L. L. Berry, and V. A. Zeithaml, "SERVQUAL: A multiple-item Scale for Measuring Consumer Perceptions of Service Quality,” J. Retail., vol. 64, no. 1, pp. 12-40, 1988, doi: 10.1016/S01482963(99)00084-3.

[4] F. Tjiptono, Strategi Pemasaran. Yogyakarta: Andi, 2005. 
[5] R. Lupiyoadi, Manajemen Pemasaran Teori dan Praktek, 1st ed. Jakarta: SALEMBA EMPAT, 2009.

[6] Sugiyono, Metode Penelitian Administrasi dilengkapi Metode $R \& D$ - MPA, 24th ed. Bandung: ALFABETA, 2017.

[7] Sugiyono, Metode Penelitian Kuantitatif, Kualitatif, dan $R \& D$ $M P K K$, 18th ed. Bandung: ALFABETA, 2014.

[8] H. Hasnih., Gunawan., "Pengaruh Lima Dimensi Kualitas Pelayanan Publik Terhadap Tingkat Kepuasan Masyarakat di Kelurahan Ompo Kecamatan Lalabata Kabupaten Soppeng,” J. Mirai Manag., vol. 1, no. 2, pp. 426-452, 2016.

[9] F. N. Mujiraharjo and M. Basuki, "Analisis Indeks Kepuasaan Masyarakat Terhadap Pelayanan Publik Bidang Kesehatan (Studi Kasus: Faskes Tingkat I Mojokerto),” no. July, 2019.

[10] A. Parasuraman, V. A. Zeithaml, and L. L. Berry, "A Conceptual Model of Service Quality and Its Implications for Future Research,” J. Mark., vol. 49, no. 4, p. 41, 1985, doi: $10.2307 / 1251430$.

[11] Febriyanto, “Analisis Gap Persepsi Pengunjung Taman Nasional Way Kambas di Lampung Timur (Studi Kasus pada Divisi Pusat Latihan Gajah),” J. Manaj. Dan Bisnis, vol. 2, pp. 53-68, 2011. 
Jimmy A. Kadar, Asep R. Hidayat Kepuasan Pelanggan Terhadap... 